\title{
Wind power prediction for onshore wind farms using neural networks
}

\author{
Bogusław Świątek, Mateusz Dutka \\ AGH University of Science and Technology \\ 30 Mickiewicza Av. 30-059 Krakow Poland \\ Phone: +48 126174067 E-mail: boswiate@agh.edu.pl, mateusz_dutka@o2.pl
}

\begin{abstract}
This paper describes some of the problems in the prediction of onshore wind farm. The possibility of using a neural network to forecast wind power production and its resistance to changing weather-terrain conditions are examined here. The effect of uneven distribution of the wind speed and direction depending on the location of the turbine are also analyzed. Three different structures of neural networks together with a comparison of efficiency of obtained forecasts are shown.
\end{abstract}

\section{Key words}

wind power forecasting, BP-neural network, abstractive thinking, efficient, balanced energy system

\section{Introduction}

The construction project of the wind farm involves high funds, it is a subject to the restrictive legislation and it is necessary to take into consideration the environmental conditions. At the same time, investors, who would like to maximize the reimbursement, try to locate as many turbines in the limited area as possible, which leads to the wake effect of wind turbines and causes turbulence in the air flow in a wind farm.

The problem of deploying turbines has been known for a long time. There are programs which help to define an optimal location of wind turbines, however, they are based on incomplete data and on only those indicators which are possible to estimate (roughness and orography of the area, obstacles, buildings) therefore, the real effect of the influence on environment and of the location is known only after construction of a power plant.

The quality of a numerical weather prediction, varied terrain (especially of the land), and the placement of turbine have a significant impact on the efficiency of wind power production. Only taking into consideration all these components, it is possible to create a high performance energy prediction model.

Neural networks have the ability to process the data simultaneously and to abstract (the ability to generalize the knowledge acquired in the learning process). These features of the neural network allow to create a tool for generating fast and efficient energy production forecasts.

The analyzed wind farm includes 15 wind turbines manufactured by Enercon GmbH Type E 70 - E4, rated power $2 \mathrm{MW}$. The average annual energy production is over $50000 \mathrm{MWh}$. The wind park with a total installed capacity $30 \mathrm{MW}$ is located on a hill with the area of 270 ha. The relative height of the plateau is about $150-170 \mathrm{~m}$ (350 - $470 \mathrm{~m}$ m.a.s.1.). The wind turbines are located approximately $450 \mathrm{~m}$ away from one another. Installation height of a generator hub is $85 \mathrm{~m}$, rotor diameter is $71 \mathrm{~m}$, swept area: $3959 \mathrm{~m}^{2}$.

\section{The influence of the location of turbines on the wind speed inside the wind farm}

An analysis of the performance of a wind power plant has been carried out with the use of the data from 20122014. The data comes from the SCADA system. These are: wind speed, wind direction and power generated by each turbine and the total power generated by the power plants recorded at intervals of 10 minutes. The stored data indicates that the wind speed and the direction in each turbine differed depending on location. Figure 1 shows a minimum, a maximum and an average wind speed recorded in each of the 15 turbines from 2 to 5 April 2014. 


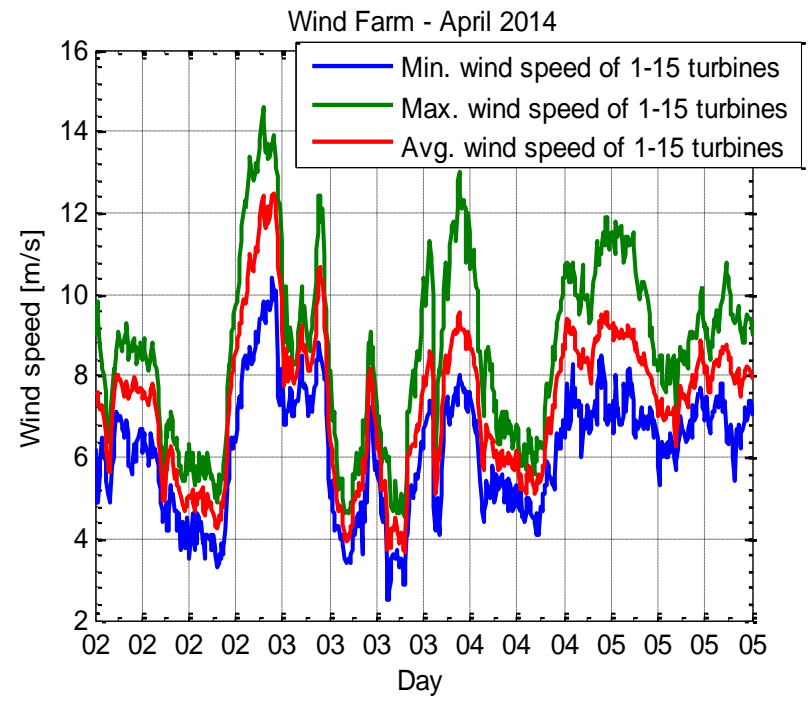

Figure 1 - Plots of the wind speed for the wind farm from 2 to 5 April 2014

A maximum and a minimum wind speed in the analyzed period differ between each other by about $2[\mathrm{~m} / \mathrm{s}]$, which is more than $30 \%$ of the average wind speed for this wind park. Assuming that the average wind speed is $6[\mathrm{~m} / \mathrm{s}]$, the speed difference is $2[\mathrm{~m} / \mathrm{s}]$ (based on the power curve) the difference in power is $386[\mathrm{~kW}]$ per turbine, which in the whole plant can give a power of even 50720 [MWh/year].

Figure 2 illustrates the average wind speed for the entire farm as a function of wind speed turbine. Turbine and its location was chosen in order to best illustrate the phenomenon:

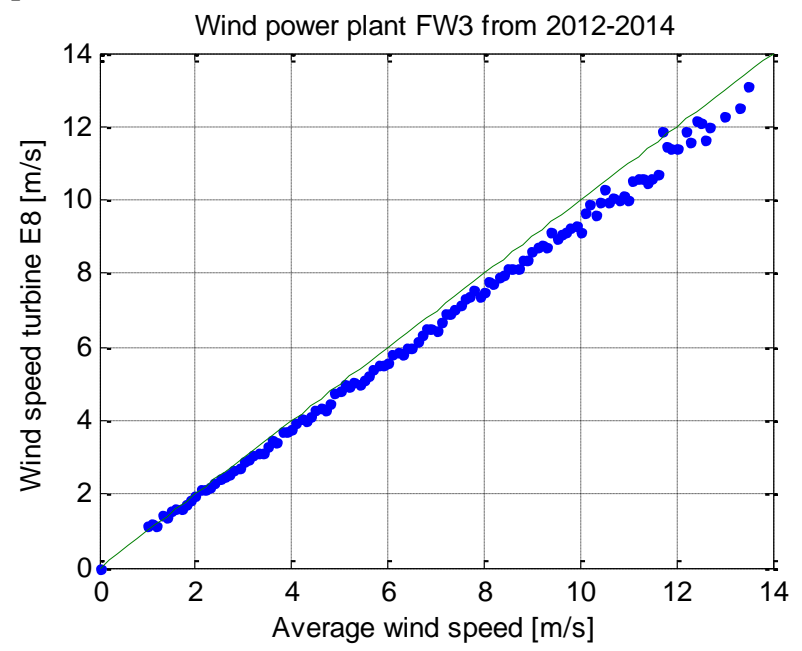

Figure 2 - Average wind speed of the wind farm as a function of wind speed turbine number 8

An analysis of individual turbines operation showed that in some locations, the wind speed recorded on a gondola, in almost the entire range of wind speed, is below or above the average wind speed for a wind farm, particularly in case of high wind speed.

In addition, a similar situation is evident in the instance of the mean wind direction angle of the entire farm, the wind direction angle of an exemplary gondola number 8 .
These values are almost in the entire range of angles from 0 to 360 above the straight line. This phenomenon is presented in Figure 3.

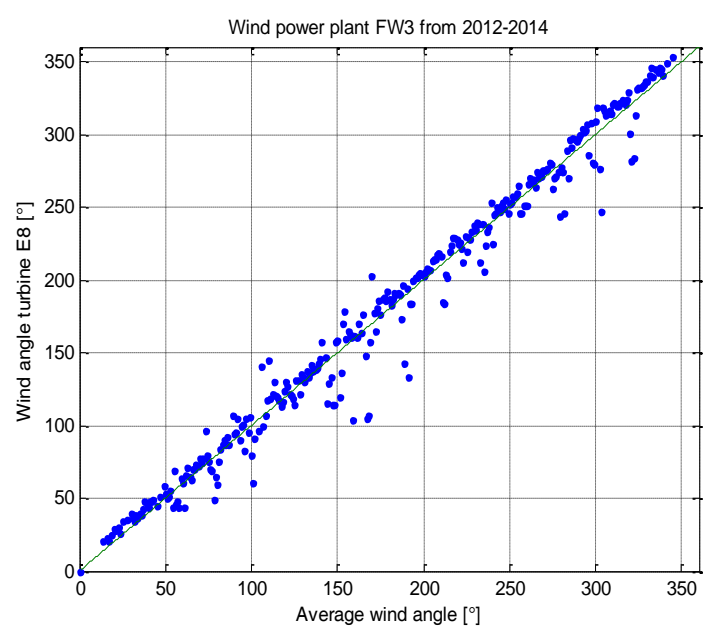

Figure 3 - Average wind direction of the wind farm as a function of wind direction for turbine 8

Observed effects canconfirm not only the influence of the meteorological conditions on the distribution of wind speed but also the mutual interaction of wind turbines by a wake effect.

\section{Building neural models when considering the environmental and location factors}

This chapter presents the results of prediction of the power output of an onshore wind farm operating at 15 turbines for three different forecasting models:

- $\quad$ Model I - $\boldsymbol{P}_{\text {out }}=\boldsymbol{f}\left(\boldsymbol{v}_{\text {avg }}\right)$

The model allows the calculation of farm output power, using the calculation of the average wind speed for the entire wind power plant (Figure 7). The principle of operation of the neural network Model 1 is shown in Figure 4. The principle of operation of Model 2 is illustrated in Figure 4.

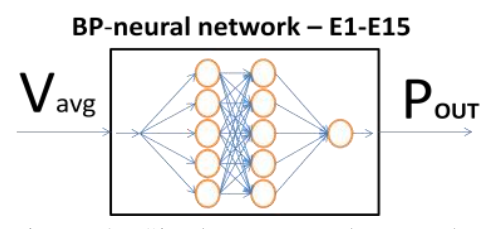

Figure 4 - Single BP-neural network

- $\quad$ Model II - $P_{\text {out }}=\sum_{i=1}^{15} f_{i}\left(v_{i}\right)$

The model consists of fifteen 3-layered unidirectional neural networks simulating the work of individual turbines in a farm. The wind speed from each independent turbine is introduced as an input in each of the fifteen neural networks simulating the turbine to operate independently. Subsequently forecasted power for all turbines is summed and output power $\boldsymbol{P}_{\text {out }}$ is obtained. The principle of operation of Model 2 is shown in Figure 5. 


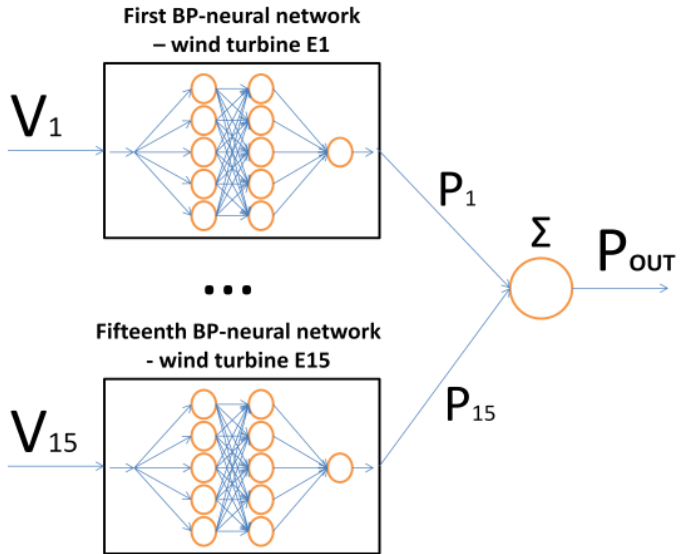

Figure 5 - Fifteen neural Network $\mathbf{V}_{\mathbf{1 - 1 5}}$

- $\quad$ Model III $-P_{\text {out }}=\sum_{i=1}^{15} f_{i}\left(v_{\text {avg }}\right)$

The model consists of fifteen 3-layered unidirectional neural networks simulating the work of individual turbines in a farm. The average wind speed from the entire wind farm is introduced as an input for each independent model. The principle of operation of Model 3 is presented in Figure 6.

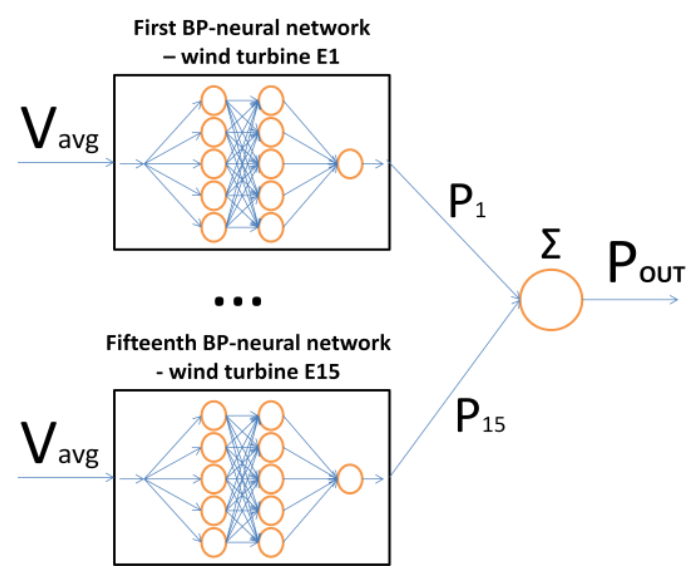

Figure 6 - Fifteen neural Network $\mathbf{V}_{\text {avg }}$

where: $\mathrm{P}_{\text {out }}$ - output power of the wind park $\mathrm{MW}, \mathrm{v}_{\mathrm{i}}$ wind speed recorded at the $\mathrm{i}$-th turbine,

$v_{\text {avg }}=\frac{\sum_{i=1}^{15} v_{i}}{15}$ - average wind speed for wind farm,

$\mathrm{f}_{\mathrm{i}}(\mathrm{)}-\mathrm{i}$-th turbine model

Table I - Summary of differences between the analyzed models

\begin{tabular}{|c|c|c|c|}
\hline \multirow{2}{*}{ Model } & \multicolumn{3}{|c|}{ BP neural network } \\
\cline { 2 - 4 } & $\begin{array}{c}\text { Number of } \\
\text { networks }\end{array}$ & Input: & Output: \\
\cline { 3 - 4 } I & 1 & $\begin{array}{c}\text { avg. for all } \\
\text { turbines }\end{array}$ & $\begin{array}{c}\text { total of the } \\
\text { farm }\end{array}$ \\
\hline II & 15 & $\begin{array}{c}\text { real for each } \\
\text { turbine }\end{array}$ & $\begin{array}{c}\text { for each } \\
\text { turbine }\end{array}$ \\
\hline III & 15 & $\begin{array}{c}\text { avg. for all } \\
\text { turbines }\end{array}$ & $\begin{array}{c}\text { for each } \\
\text { turbine }\end{array}$ \\
\hline
\end{tabular}

Figure 7 shows the location of the turbines within a wind farm, and illustrates the problem of uneven distribution of wind speed and its direction.

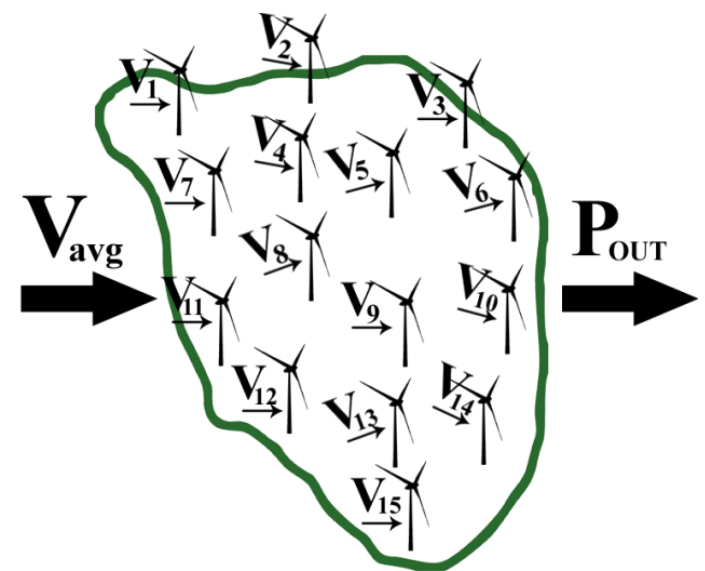

Figure 7 - Location of turbines in a wind park

In each model 3-layer unidirectional neural network containing in the first two layers 5 neurons of the logsigmoid transfer function and a single linear neuron in the output layer. Training set (wind speed and power generated by wind turbines) was organized on the basis of the data from 2012-2013 - one full year. Training set was built with more than 52,000 vectors consisting of the date and time, the real wind speeds for each turbine independently, the real power generated by each turbine, and the mean values of wind speed and power of the entire wind farm. Data vectors were registered with the SCADA system with a time interval of 10 minutes. The neural network was built using back propagation (BP-neural network) and the Levenberg-Marquard algorithm. The verification of the models was performed using the the real weather data (wind speed) from 06/01/2013 to $05 / 31 / 2014$. The training and verifying sets were selected in such a way to get one full year, including all four seasons, and the phenomena associated with them. As observed in the analysis, the quality of prediction varies depending on the seasons.

The real power curve of a wind turbine and curves resulting from the predictions for the analyzed models presented in Figure 8.

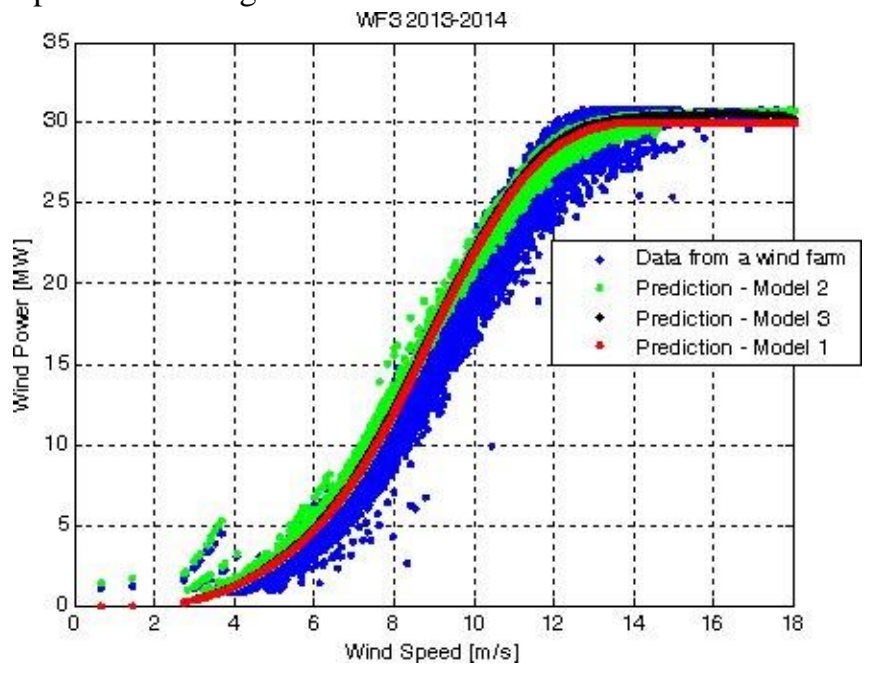

Figure 8 - Wind farm power curve 
The real power curve of a wind power plant strongly deviates from the theoretical waveforms declared by the manufacturers of wind turbines. These analyzes are performed basing on the ideal laboratory climate conditions. In practice, the strength of the wind, temperature, and pressure change over time. There are strong, but short gusts of wind, which do not allow for stable operation of the wind turbine. The proposed prediction models using neural networks allow to, depending on the forecast, more or less reproduce the actual power curve.

The evaluation of efficiency of the models was carried out by comparing:

- the mean absolute forecast error MAE, mean absolute percentage error MAPE and mean absolute deviation MAD.

$$
\begin{gathered}
M A E=\frac{1}{n} \sum_{t}\left|P_{\text {real }}(t)-P_{\text {out }}(t)\right|=\frac{1}{n} \sum_{t}\left|e_{i}\right| \\
M A P E=\frac{1}{n} \sum_{t}\left|\frac{\left(P_{\text {real }}(t)-P_{\text {out }}(t)\right)}{P_{\text {real }}(t)}\right| \cdot 100 \% \\
M A D=\frac{1}{n} \sum_{t}\left|e_{i}(t)-\bar{e}(t)\right|
\end{gathered}
$$

where $e_{i}=\left|P_{\text {real }}(t)-P_{\text {out }}(t)\right|, \bar{e}$ - average error.

- Frequency of obtaining forecast with the accuracy of $0.75 \mathrm{MW}$ and $1.5 \mathrm{MW}$ which corresponds to $\pm 2.5 \%$ and $\pm 5 \%$ of the installed capacity of wind

- the annual average forecast error $\frac{\sum_{i=1}^{n}\left|e_{i}\right|}{\sum P_{\text {out }}}$, annual error of revaluation and the underestimation of energy generated.

The results are illustrated in Figure 9, Figure 10 and Figure 11.

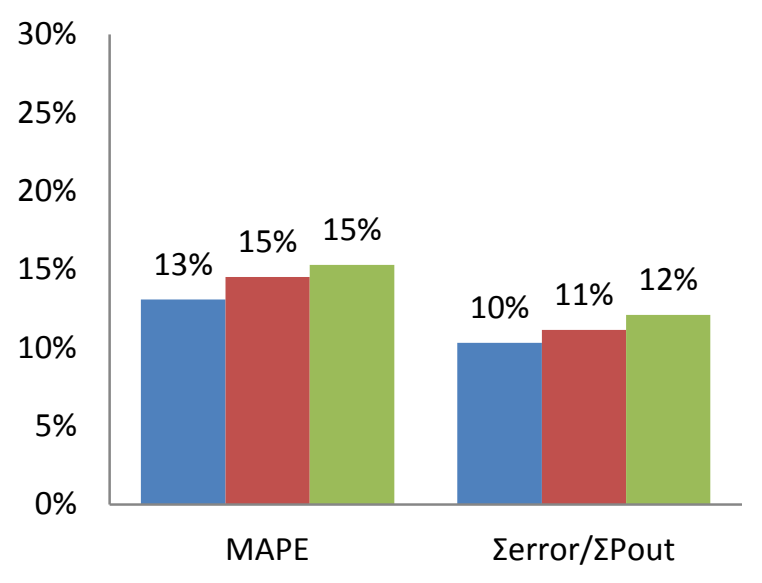

Model 1 Model $2 \quad$ Model 3

Figure 9 - Summary of performance models MAPE and the average annual forecast error

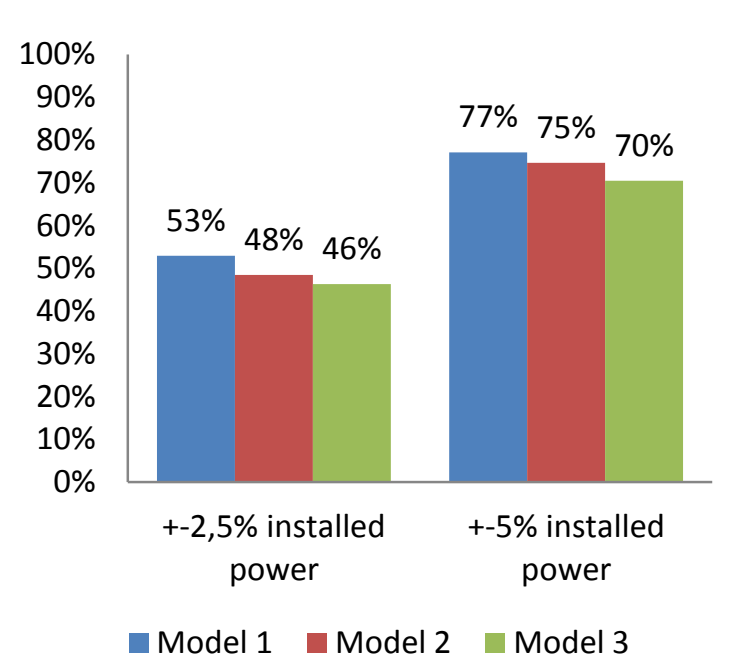

Figure 10 - Summary of performance models: errors within the set of $2.5 \%$ and $\pm 5 \%$ of the installed power

During the analysis it was observed that the quality of forecast varies depending on months and seasons. The variability of this is shown in Figure 11.

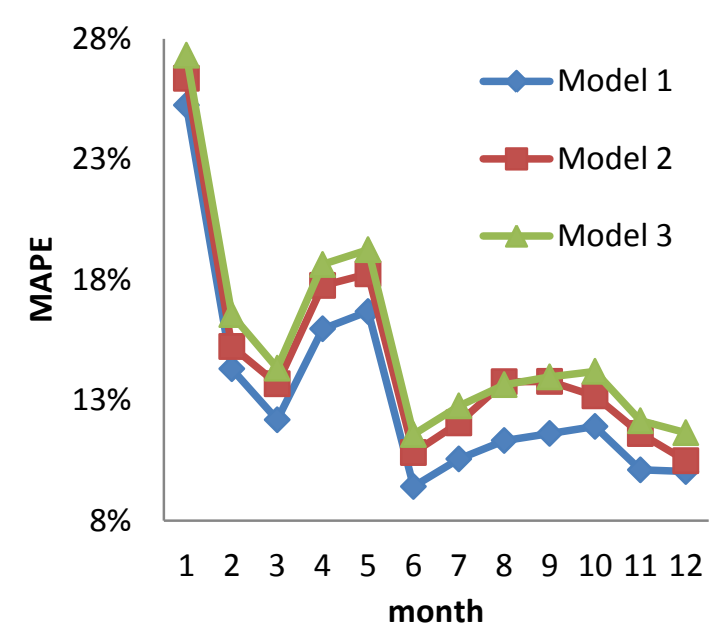

Figure 11 - Monthly mean absolute percentage error

The biggest prediction MAPE appeared in the winter months, especially in January, where the weather was very diverse, both in terms of wind speeds and temperatures. The most predictable proved to be the month of June in which the forecast error was: Model $1-9 \%$, Model 2 $11 \%$, Model $3-12 \%$. Throughout the analyzed period of one year, MAPE error was the smallest for the simplest Model 1 with regard to both monthly and annual period.

The owners of wind power plants are required to submit production plans for the next day. Each error is directly related to any charges resulting from the need to change production plans in the energy system and energy balancing strategy. Table II shows the forecast errors for the analyzed period of one year in which the total energy generated by wind power amounted to 60775 [MWh]. 

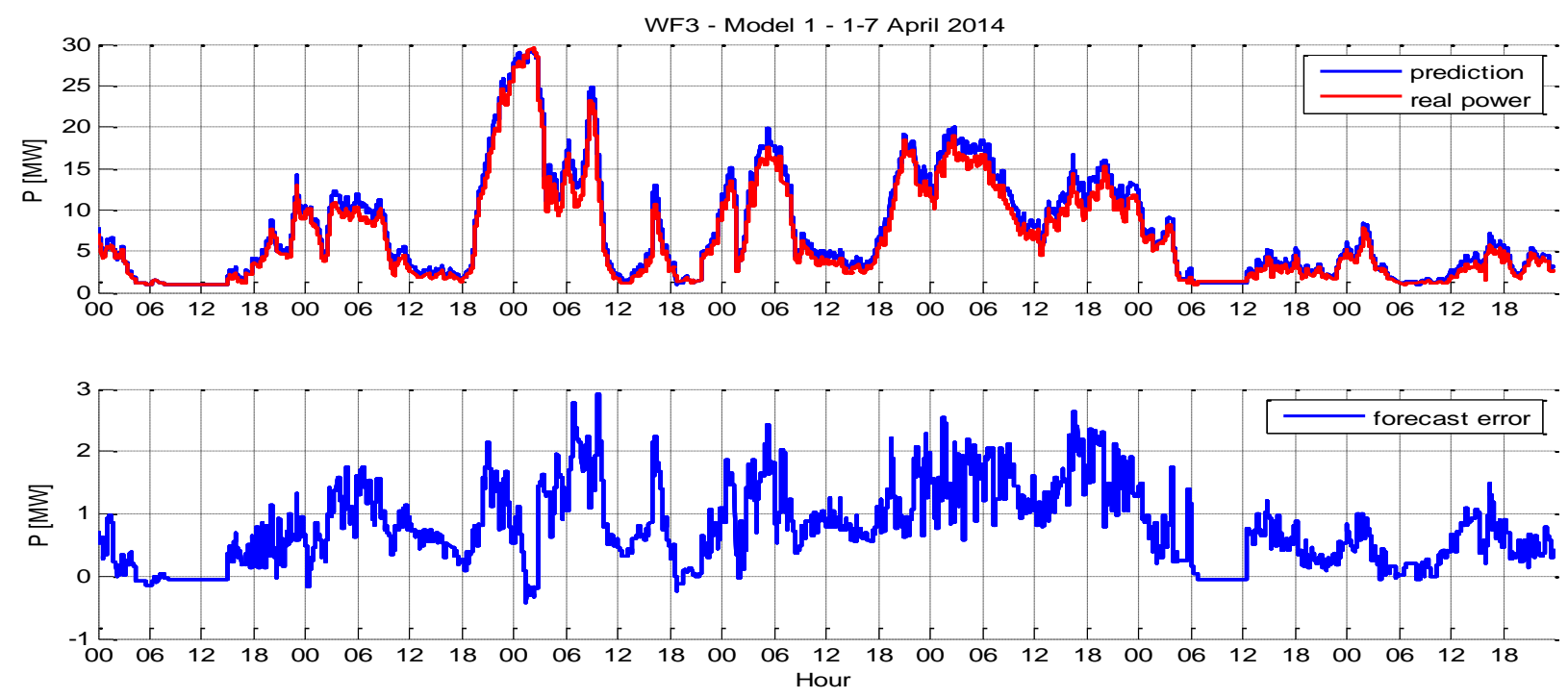

Figure 12 - Sample production forecast made for Model 1 for 04/01/2014 to 04/07/2014

Table II - Summary of the annual amount of errors

\begin{tabular}{|c|c|c|c|}
\hline \multirow{2}{*}{ Model } & \multicolumn{3}{|c|}{ The annual amount of errors } \\
\cline { 2 - 4 } & $\begin{array}{c}\text { output } \\
{[\mathrm{MWh}]}\end{array}$ & $\begin{array}{c}\text { revaluation } \\
{[\mathrm{MWh}]}\end{array}$ & $\begin{array}{c}\text { underestimation } \\
{[\mathrm{MWh}]}\end{array}$ \\
\hline 1 & 6147 & 5992 & 156 \\
\hline 2 & 6621 & 6547 & 74 \\
\hline 3 & 7183 & 7086 & 97 \\
\hline
\end{tabular}

Figure 12 shows a demonstrative comparison of the forecasts of electricity production for Model 1 (top graph in blue) and the actual production of energy (top graph in red). The lower graph shows the forecast error for one week in April. In the period from 04.01.2014 to 04.07.2014 forecast error, despite the strongly varying wind speed and energy production farm, was less than $10 \%$ of installed capacity.

Figure 13, Figure 14, Figure 15 illustrate the frequency histograms of relative errors. They confirm that the models overestimated the value generated by the energy the majority of bars is located to the right of zero.

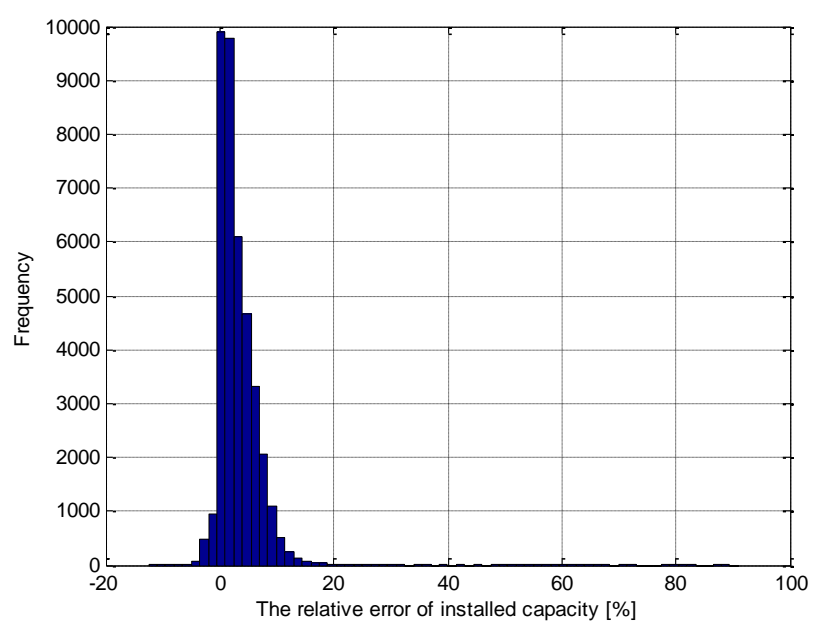

Figure 13 - Annual relative error of installed capacity - Model 1



Figure 14 - Annual relative error of installed capacity - Model 2

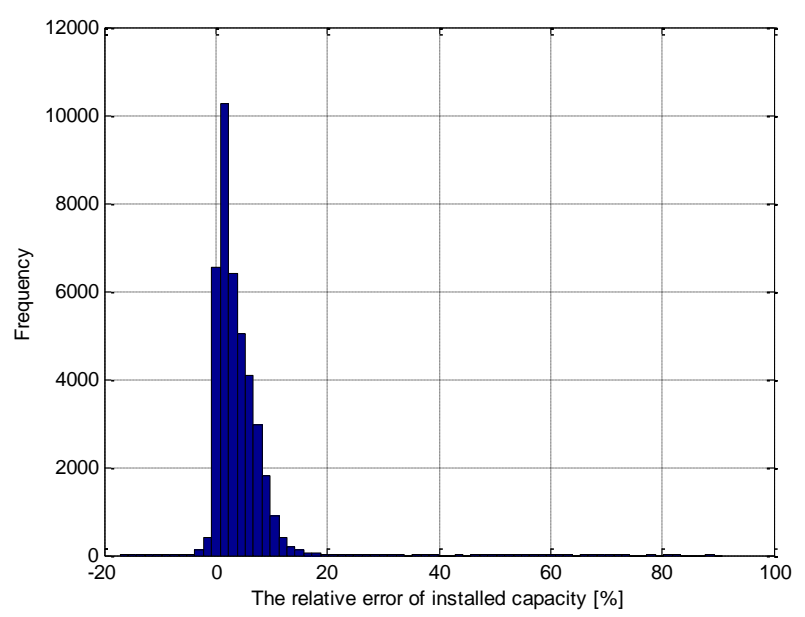

Figure 15 - Annual relative error of installed capacity - Model 3

The proposed prediction models overestimate energy production in almost the entire range of prediction. This is confirmed by Table II and histograms. Standing error occurring in all three models can be a reason to choose the 
wrong training set, containing not enough anomaly events, so the model is not able to properly react in case of such a phenomenon.

The annual rate of MAE and MAD is illustrated in Figure 16.

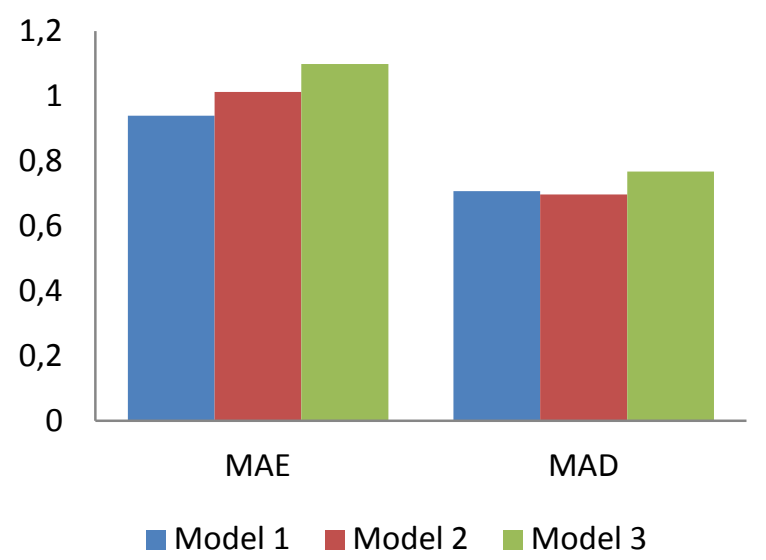

Figure 16 - Annual MAE and MAD for three forecasting models

MAE and MAD coefficients are calculated for a long time period of one year in which a number of unpredictable weather anomalies and temporary shutdown of turbines may occur, for example, due to technical reasons, which could be the reason for the high values of MAE in the analyzed period. MAD coefficient on obtained level confirms the low error variability. The elimination of the presence of constant error will allow to obtain better forecast results of electricity production in the analyzed wind farm in the future.

\section{Conclusion}

The results of the study indicate that the first and simplest model shows the highest precision. This is due to the ability of the neural network to approximate nonlinear function. Neural network in the learning process finds a relationship between wind speed and location of individual turbines; and the power generated by the plant.

Forecasting method using neural networks has generated satisfactory results of prediction. When considering the choice of a variety of structures, a strong correlation between the quality of forecasts and selected training set was observed. As the analysis shows, the wind speed forecast had the greatest impact on the performance of prediction.

Despite the occurrence of uneven pattern of wind speed and direction in the area of the wind farm, neural networks based on the average input (average wind speed - model 1 and 3) made it possible to generate comparable forecasts of neural network based on actual data for each turbine individually (model 2). This feature of BP-Neural Network can be useful if using Numerical Weather Prediction (NWP), which allows to forecast the weather with limited precision e.g. the average hourly wind speed and direction for the whole wind farm. Taking advantage of neural networks, in particular the ability to process the data simultaneously and to abstract, made it possible to generate fast and efficient energy production forecasts for all three models.

Clearly, there is still a large potential in this forecasting method. This method of prediction, after the introduction of improvements, will be able to support the work of the wind farm and power system - increasing its stability, which in Polish conditions, will reduce the loss of energy and emissions of $\mathrm{CO} 2$ to the environment by minimizing „hot” power reserve (reducing the amount of coal burnt). Increasing the accuracy of numerical weather prediction, further optimization of network structure (number of: networks, neurons and layers, selecting the best method of learning), the introduction of new improvements by increasing the number and selecting appropriate relevant inputs of neural network will provide better results in the future.

\section{Acknowledgement}

This work was supported by the AGH University of Science and Technology under European Regional Development Found, Subsidy No POiG.01.03.01-30056/12.

\section{References}

[1] D. Wu, H. Wang, "Application of BP neural network to power predioction of wind power generation unit in microgrid", Engineering Technology and Applications, London 2014.

[2] Wen-Yeau Chang, "Short-Term Wind Power Forecasting Using the Enhanced Particle Swarm Optimization Based Hybrid Method", Energies 2013, 6, 4879-4896.

[3] Z. Liu, W.Gao, Y.-H. Wan, E. Muljadi, "Wind Power Plant Prediction by Using Neural Network", IEEE Energy Conversion Conference and Exposition, August 2012.

[4] M. Qi, G. P. Zhang, "Trend Time Series Modeling and Forecasting With Neural Networks", IEEE Transactions on neural networks, vol. 19, no. 5, May 2008 